\title{
Research on the modernization of tax governance capacity
}

$$
\text { Siming Zhang }{ }^{1, a} \text {,Yue Zhang }{ }^{2, b} \text {,Tiantian Guo }{ }^{3, c}
$$

${ }^{1}$ Capital University of Economics and Business, Law school, Beijing, China

${ }^{2}$ Capital University of Economics and Business, Law school, Beijing, China

${ }^{3}$ Capital University of Economics and Business, Law school, Beijing, China a1961009805@qq.com, b769497917@qq.com, c424320342@qq.com

\begin{abstract}
Keywords: Revenue management, statutory tax, Credit system, Public participation
\end{abstract}
\begin{abstract}
In this article, we found three problems that exists in tax administration process through the analysis of the connotation of tax management and the status quo of China's current tax management, such as, the construction of the rule of law is not sound and the tax law system is not perfect, the subject is not clear and the relationship between the power and responsibility is vague, the governance pattern is backward and the policy transparency is low. On this basis, found some relevant solutions. On the one hand, we should perfect the tax law system makes the tax authority in the process of law enforcement to better adhere to the tax revenue legal principle, speed up transformation of the functions of the tax authority, on the other hand, should also blamed on taxpayers, perfect the public engagement for tax activities. Even more it should also promote the scientific nature of tax governance, promote the compliance of citizens' tax laws, improve and establish credit system, rationally use science and technology, and properly carry out information sharing. It is hoped that through these methods, we can promote the modernization of China's tax governance capacity.
\end{abstract}

\author{
税收治理能力现代化问题探究 \\ 张思名 ${ }^{1, a}$, 张悦 ${ }^{2, b}$, 郭田甜 ${ }^{3, c}$ \\ 1 首都经济贸易大学法学院, 北京, 中国 \\ 2 首都经济贸易大学法学院, 北京, 中国 \\ 3 首都经济贸易大学法学院, 北京, 中国 \\ a1961009805@qq.com,b769497917@qq.com,c 424320342@qq.com
}

关键词:税收治理 税收法定 信用体系 公众参与

中文摘要: 本文主要是通过分析税收治理的内涵以及我国目前税收治理的现状, 找到了税收治 理过程中存在的法治建设不健全, 税法体系不完善、主体定位不清, 征纳权责关系模糊和治 理格局落后, 政策公开透明度低等三个主要问题。在此基础上, 找到了几个相应的解决办法, 我们不仅要完善税法体系使税务机关在执法过程中更好地坚持税收法定原则, 推进征税机关 的职能转变, 还应该还责于纳税人, 完善公众对纳税活动的参与力度, 更要提升税收治理的 科学性, 促进公民的税法遵从, 完善和建立信用体系, 合理利用科学技术, 适当开展信息共 享。希望通过这些方法, 能够促进我国的税收治理能力现代化建设。 


\section{1. 引言}

党的十八届三中全会从国家治理体系方面和治理能力的角度对税法治理提出了总体要 求, 要求税法机关要贯彻执行税收法定的原则, 并建立健全我国目前的税收制度。张宝雷学 者提出了从体制、人才和税法等三个方面提出了提升税收治理能力现代化的建议; 秦泮义学 者则独辟蹊径提出从创新理念来解决税收治理的问题; 还有学者从税收治理的内涵出发来分 析税收治理的各种问题, 并找到了相应的解决办法。

\section{1 税收治理的内涵}

国家依据制度性和非制度性的计划在多种主体之间对税收权力和资源进行适当配置和使 用, 通过多种主体在平等、自愿、民主、公平的基础之上的沟通合作，达到引导、控制、管 理、协调和服务税收目的的活动叫做税收治理。税收治理能力是国家治理能力的重要表现, 税收治理体系是国家治理体系中非常重要的一部分。想要实现税收的现代化, 关键的是提高 税收的治理能力, 建立现代化税收治理体系。因此, 通过分析我国目前税收治理能力的现状, 找到当前我国税收治理过程中存在的问题, 并提出相应的解决办法, 具有实际的指导意义。

\section{2. 我国税收治理存在的问题}

\section{1 法治建设不健全, 税法体系不完善}

目前在我国的许多税种中，税法的法律位阶比较低，已经立法的只有四个: 企业所得税、 个人所得税、车船税和环保税，其余大多数税种是由全国人民代表大会授权国务院、国务院 再转授权给财政部及国家税务总局制定一些法规或部门规章。这样的立法与我国所确立的税 收法定原则相违背, 所以在执法和征税过程中会遇到较多的问题。所谓的税收法定是指, 征 什么税、向何人征税、如何征税都应该由法律明确规定, 如果法律没有明确规定义务人该交 的税, 义务人是有权利拒绝交税的, 但在一些位阶较低的税种中又规定了某种税, 那相对人 该不该交, 该如何交, 就会在义务人与税务机关之间产生矛盾。长此以往, 纳税义务人会对 纳税产生抵触心理, 不愿意交税, 甚至是采用违法手段偷税、漏税。这样不仅是不利于税务 机关的执法, 还不利于我国征税工作的进行。

\section{2 主体定位不清, 征纳权责关系模糊}

目前我国税务机关对纳税义务人的干涉太多，虽然我国税收征管的模式已经历经了多次 修改, 但是征税部门“保姆式”的管理方法仍未从根本上有所改变。这样不仅会滋生纳税义务 人的惰性心理, 每次交税都需要税务机关多次催促才肯履行自己的纳税义务, 而且还不利于 贯彻执行税务廉政规则, 并且会加大税务工作人员的执法风险与难度。税务机关如果不能清 楚的认识到纳税人是税收的主体, 并且还对纳税人的行为进行不必要的干涉, 那税收的征管 工作将会难以进行, 征税机关和纳税人也会互相不信任, 不利于税收治理能力的提升。

从立法层面来说, 各类税种的实体法律制度中早就体现了税收收入的规模。税法也对许 多要素都做了明确的规定如: 税率、征税范围、课税对象等。所以, 税收收入的多少主要取 决于经济发展的现状以及经济的发展水平。根据依法行政和税收法定原则的规定, 保证税法 的贯彻与执行是税务机关最重要的使命和职责, 也就是美国实行的税法遵从, 维持税收的秩 序稳定, 确保税收的公正与公平。正如 《OECD 良好税务管理的原则》中所写的, “保证税 收法律的合理性是税收管理机构的重要职责”。我国目前有许多偷税、漏税的情况, 以及不少 明星通过加入其它国籍、某些公司在国外挂名设立等来减少税收的情况, 都反映出我国目前 的税收利率不在人们能接受的范围之内，所以民众才会想法设法的去避税。

\section{3 治理格局落后, 政策公开透明度低}

目前我国, 税务机关和纳税义务人是参与税收治理活动的两个主体。税收治理能力现代 
化思想不仅注重税务机关内部的协作还注重税务机关与外部协同。从这个角度来说,税收治理 的现代化不仅仅是税务部门一个系统的事情,还需要各政府部门互相协助来完成的事情。但在 实际情况中税收治理常常是征税机关自己对税收活动的整个过程进行计划、决定、组织、协 调和监督控制, 以确保税收的职能和使命能够实现的一种管理活动。征税活动仅凭税务机关自 身是很难完成, 纳税人的各项信息税务机关自身的掌握并不全面, 如果税务机关凭借不全面 的信息来向纳税人征税，会造成多征或少征的情况出现。

税收政策公开透明度不高, 国家征税的目的是为国家聚揽财富, 为公民的公共利益收税, 所以应进一步保障纳税人和民众合理合法的参与权、知情权、表达权和监督权。纳税人不仅 有权知道自己缴纳的税款干什么用了, 并且还有权监督其贯彻执行。政府也要公开税款的分 配和用途, 不能只能纳税人承担义务而不能享受其应有的权利。存在这些问题的主要原因有 两个: 一个是现行的宪法和税法没有明确规定公众参与税收治理活动的权利; 另一个是一直 以来税收机关对税法的和纳税工作宣传不到位, 老百姓缺乏对税收的了解与认知, 再加上公 民普遍缺乏权利意识，所以公民对税收治理活动的参与能力是有限的。

\section{3 解决方案}

\section{1 要完善税法体系, 坚持税收法定}

一是, 如果有些税法的法规和部门规章在实践中证实了其是科学的、有效的那就应该及 时让全国人大上升它为法律, 提高税法的位阶, 使之与我国的税收法定原则相适应, 税务机 关在执法过程中也可以“有法可依”, 这样可以在很大程度上缓解税务机关和纳税人之间的矛 盾和分歧; 如果一些法律法规不能适应经济的发展和社会的进步就应该及时废除或修改, 不 合适社会发展的法律就相当于恶法，不可能达到法律所追求的目标，也不能让民众信服，所 以老百姓也不会自愿遵守税法, 主动缴纳税款。法律贵在它的时效性, 立法机关应该经常审 查法律，使其符合经济的发展，为社会的进步提供服务。

二是使法治原则在税收治理过程中得以贯彻执行。在组织税收过程中坚定不移的实行“依 法征税、应收尽收, 坚决不收过头税, 坚决预防和杜绝越权减免税”这一原则; 在税收执法中 要讲证据、看事实、走程序; 在征税服务中, 要充分尊重纳税义务人的主体地位, 坚决维护 纳税人合法的权利与利益。税务机关及其工作人员在执法过程中一定要牢记法治原则, 法律 所规定的权力自己才可以行使, 法律没有明确规定的权利绝不越权, 坚决依法办事。税务机 关及其工作人员也要充分保障纳税人的权利, 明确自身服务于纳税人的地位, 帮助纳税人顺 利完成纳税工作。

\section{2 促进公众参与, 还责于纳税人}

税务机关一定要充分尊重纳税义务人的主体地位, 对税务机关工作人员的职责重新定位, 解决好征税机关和纳税义务人权责不清、权责错位等一系列的问题。一方面, 要积极提倡“诚 信推定”理念, 彻底改变过去的申报期内税务机关提前催报或是直接代替纳税人申报等“保姆 式”管理方式, 只需要强化未按时申报的后续处理方式即可, 主要注重纳税人自愿地履行其自 身的纳税义务，使纳税成为公民乐此不疲的事。

只有纳税义务人积极地参与互动活动, 税务机关才能够及时清楚的知道纳税人的各种需 求, 以此作为科学决策的参考, 并且还有利于征税机关和纳税人之间相互信任, 树立税务机 关为民服务的良好形象。想要提高公民参与的积极性, 就要建立健全有关税收的法律, 设立 制度机制让公众参与到税收治理活动中, 明确地规定纳税人和公众在税收方面的参与权; 开 拓纳税义务人参与税收治理的渠道和方法, 使纳税人及公众的需要一定要得到满足。

\section{3 促进税法遵从, 完善信用体系}

自从进行了“营改增”之后, 我国也正在积极迅速地进行新一轮的税制改革方案。与此同 
时, 我国也应该适当地健全目前的税收征管制度, 重新认识和定位征税机关的职责, 改变我 国目前的税收治理观念, 税务机关要全力为纳税人提供方便和服务, 以便其能依法履行纳税 义务, 并对那些不愿遵从税法的人们进行严厉的处理和打击。所以, 想要实现税收治理能力 的现代化建设, 第一步就需要进一步清楚和确认税务机关的职责和使命, 将纳税服务的观念 牢记在心里, 一定要以纳税人为本, 税务机关要将“促进公平、公正执法, 提高税法遵从度” 作为自己的奋斗目标。税法的制定应该是一个国家跟纳税人协商的结果, 立法机关不能仅凭 自己的判断就制定税法, 明确应该征什么税, 征多少税, 如何征税等, 这样的方法是非常不 科学的。所以目前我国的税收治理应该加强和纳税人的协商, 这样才能提高纳税人的税法遵 从，人民自愿遵守自己所同意的法律。

第二步, 就是要建立和完善信用体系, 在一个社会中经济得以发展的重中之重就是必须 要健全的整个社会的信用体系。其中社会信用的建立是以纳税信用的建立为基础的, 建立有 关纳税方面的信用制度对加快整个社会信用体系的建设具有非常重要的作用。建立纳税人诚 信体系, 逐渐地将纳税方面的诚信记录跟社会诚信体系相结合, 加大对诚信行为的鼓励力度 并严惩失信的行为,在整个社会营造出诚信纳税的氛围。

税务机关的宗旨应该是提高纳税人的税法遵从, 坚定不移的对诚信行为进行表扬并且对 实行行为给予严厉的惩戒, 积极努力地建设社会信用体系, 以完善市纳税义务人的纳税信用 信息为手段, 成立一种奖惩机制——诚信奖励、失信惩罚, 希望可以为诚实守信的纳税人给 予便捷服务和实质性帮助, 对于那些不诚信的信纳税人给予通报批评、曝光等惩罚, 税收管 理方面的创新需要以纳税信用来推动, 以此来推动整个社会信用体系的建设。这样的话, 一 则可以对那些不愿意遵从税法的公众们进行信用上的约束, 一旦在税收诚信记录方面有了不 良记录, 就会对该纳税人在整个社会上的诚信产生不利影响, 进而会大大影响该纳税人在投 资等生产经营方面的活动, 这样对纳税人自觉遵从税法产生促进作用; 二则有关税务方面数 据的公开和运用, 也会促使全社会对税法工作的高度关注, 有利于良好的征税纳税环境的形 成, 最终税法遵从的程度会大大提高, 纳税工作也会更好地开展。

\section{4 合理利用科学技术, 适当开展信息共享}

在这个信息共享和互联网发达的时代, 不少学者提出用新的科学技术和信息共享的手段 来解决税收治理问题, 但笔者有不同的观点, 我国目前的网络人才和科学技术水平都有待提 高, 如果在税收中将纳税人的各项信息都汇集在税务机关, 这些信息的来源肯定是非常可靠 和真实的, 但大家都疏忽了一个重要的问题, 就是信息安全。在今年出现的准大学生被骗后 自杀的事件中就是由于教育部门的信息泄露才造成了悲剧的。笔者并不建议完全利用科学技 术实现信息共享, 所以在税收治理过程中要合理利用科学技术进行信息共享, 维护民众的信 息安全比完成纳税工作更重要。

因此，我国目前还应该做的一件事就是，培养专门的税法人才，发展专门的税法科技， 这些都需要政府的政策导向。经济法是近些年来才发展起来法律, 加上我国的市场经济跟发 达国家的市场经济有很大的不同, 所以我们的经济法法发展更多的只能是依靠自己, 而不能 过多的借鉴国外。而想要税法跟我国的实际相符还需要我国自己来发展自己的税法, 外国能 给我们的借鉴并不多, 国内研究税法的人也为数不多。但税法的发展对我国经济的发展起着 至关重要的作用, 要想我国的经济可以平稳健康的法展, 必须要大力发展税法。专门的工作 人员才能更好地为我国的税务工作服务, 他们具有较高的专业性知识, 处理跟纳税人的各种 矛盾纠纷也更有效率。

\section{References:}

[1] Research Group of Local Tax Bureau of Zhangzhou City in Fujian Province, the Existing Problems and Method Selection of Tax Governance, Tax Research,09-2016. 
[2] Qin, Panyi, Promote the Modernization Construction of Tax Governance Ability by Concepts Innovation, Tax Economy Research,02-2015.

[3] Zhang, Leibao, Tax Governance Modernization: From Reality to Realization, Tax Management, 10-2015.

[4] Wang, Liude, The Challenges and Opportunities of Tax Governance Ability Modernization under the Background of "Internet+", Finance Observation, 11-2016.

[5] Yao, Xuange. Promote National Government Modernization by Taxation Law. Shenzhen Special Zone Daily, 10-2014.

[6] Gao, Peiyong. On the New Stage of Perfecting Tax System, Economy Research.50-02, 2015.

[7] Zhang, Jinghua. The Ability of Tax and Governance: Transnational Empirical Test,Finance \& Trade Economics , 11-2016. 